\title{
A EVOLUGÃ̃ DA PARTICIPAGÁ̃ FEMININA NO MERCADO DE TRABALHO BRASILEIRO DE 1983 A 1988
}

\author{
Eleonora Cruz Santos* \\ Guilherme Luis Sedlacek**
}

\section{Resumo}

Este trabalho analisa a participação feminina no mercado de trabalho brasileiro e sua evolução no período de 1983 a 1988 . Notamos um rápido aumento da proporção de mulheres trabalhando no período, que passa de $41 \%$ em 1983 para $46 \%$ em 1988. Dentre a multiplicidade de fatores que explicam a probabilidade da mulher trabalhar nesta análise destacamos a importância de diferenças de estado conjugal. Em 1988, observamos que a proporçào das mulheres trabalhando era de $70 \%$ entre as chefe domicílio e de $39 \%$ entre as cônjuges. Neste contexto, observamos um aumento da importância relativa das mulheres cônjuges no mercado de trabalho feminino entre 1983 e 1988. Numa parte final do trabalho, constrastamos as características do mercado de trabalho feminino nas diferentes áreas metropolitanas do Brasil.

Palavras Chaves: Mercado de trabalho brasileiro, participação feminina no mercado de trabalho, esposas no mercado de trabalho.

\begin{abstract}
This work analyse the female participation in the brazilian labor market and its evolution in the period from 1983 to 1988. We noted a rapid increase in the proportion of working women in this period, which goes from $41 \%$ in 1983 to $46 \%$ in 1988 . Within the multiple factors which explain the probability of a women to work, in this analysis we emphasize the importance of differences in marital status. In 1988, we observe that the proportion of working women was $70 \%$ among the females family heads, and only $39 \%$ among the spouses. In this context, we observe an increase in the importance of spouses in the female work force between 1983 and 1988. In the last part of the work, we compare the differences the different
\end{abstract}

Kew words: Brazilian labor market, female labor force participation, working spouses.

\section{Introdução.}

A participação feminina no mercado de trabalho tem uma multiplicidade de fatores determinantes. Por muitas vezes, as

*Pesquisadora Visitante do IPEA-RIO
**Do IPEA-RIO

R. de Econometria Rio de Janeiro v. X, n² 2, p.225-241 novembro 1990 
mulheres exercem outras atividades além das tarefas domésticas e nem sempre elas entram no mercado de trabalho como decorrência da decisão de cuidar dos filhos. O estado conjugal é, possivelmente, a variável mais importante na distinção de padrões diferentes de participação. No Brasil, evidencia-se o elevado crescimento da taxa de participação das mulheres cônjuges ao longo da década de 80 , grupo esse composto, em 1989 , por aproximadamente $56 \%$ da população feminina e por $47 \%$ das mulheres que trabalham, resp ectivamente.

A análise refere-se ao Brasil e às Regiões Metropolitanas investigadas pela Pesquisa Nacional por Amostra de Domicílios PNAD - no período de 1983 a 1988. O universo de mulheres restringe-se ao grupo etário de 15 a 54 anos de idade residentes em domicílios particulares.

Uma análise do período de 1983 a 1988 nos permite extrair resultados relativamente importantes da dinâmica da participação da mulher no mercado de trabalho brasileiro e metropolitano. $\mathrm{O}$ conhecimento dessa dinâmica pode contribuir de forma significativa para a formulação de politicas compensatórias, ou simplesmente para entender o significado das estatísticas de emprego. Adicionalmente, o conhecimento dessa dinâmica levanta questões relevantes para projeções de oferta de mão-de-obra a curto e médio prazos.

O presente trabalho está organizado da seguinte forma: primeiramente, fazemos uma análise sumária da participação feminina no mercado de trabalho brasileiro e sua evolução no passado recente (de 1983 a 1988). A seguir, procuramos destacar a importância relativa das mulheres cônjuges neste mercado e contrastar as características do mercado de trabalho feminino nas áreas metropolitanas com as características do mesmo mercado para todo o Brasil. Por fim, na última seção, apresentamos nossas conclusões.

\section{Uma caracterização geral do mercado de trabalho bra- sileiro.}

A análise da participação feminina dentro de um contexto de decisões da família, tem sido objetivo de vários estudos. ${ }^{1}$ Dentre eles Durand (1975), num estudo onde tenta traçar um padrão de

${ }^{1}$ Uma vasta literatura tem tratado desta questão, onde podemos citar Bar- 
taxas de atividade femininas e masculinas abrangendo 150 paises, sugere que o padrão de participação feminino apresenta-se extremamente vulnerável a mudanças na estrutura de demanda por mão-de-obra, a variações no nivel de renda e salários, a taxas de desempregos, e a outros fatores extra-econômicos. Segundo esse autor, o ciclo de vida da participação da mulher na força de trabalho não é bem definido, além de ser usualmente associado ao ciclo de vida do casamento e da família. ${ }^{2}$

Kreps e Clark (1975) corroboram na tentativa de definir o padrão de participação das mulheres no mercado de trabalho e argumentam que, a participação das mulheres casadas na força de trabalho é uma função (i) da idade e da escolaridade da esposa, (ii) do número e da idade dos filhos, (iii) da posição ocupacional do marido, e, (iv) de outras fontes de renda familiar. Esses autores também argumentam que os fatores que afetam as taxas de atividade femininas são: mulheres com níveis mais altos de instrução; o declínio da fecundidade; o crescimento relativo dos salários femininos; e, uma maior aceitação social de mulheres solteiras e/ou casadas que trabalham. ${ }^{3}$ Kreps (1971) acrescenta que a probabilidade de uma mulher trabalhar é influenciada, principalmente, por seu estado civil.

Diante deste contexto podemos argumentar, por hipótese, que variações na taxa de participação das mulheres cônjuges no mercado de trabalho constitui-se num elemento fundamental para a determinação da capacidade da família de se adaptar a crises no mercado de trabalho brasileiro. Este argumento encontra forte fundamentação em estudos desenvolvidos por Jatobá (1989). Segundo esse autor, os trabalhadores secundários, e entre eles as mulheres, apresentam uma maior sensibilidade da sua participação na

ros e Mendonça (1990), Oliveira e Santos (1990), Jatobá (1989), Zylberstajn, Pagotto e Pastore (1985), Pastore, Zylberstajn e Pagotto (1983), Silva (1982), Paiva (1980), Bilac (1978), Durand (1975), Kreps e Clark (1975), Kreps (1971).

${ }^{2}$ Observa-se, desde 1940, uma mudança no comportamento das mulheres casadas no grupo etário de 30 anos e mais que, ao invés de pernnanecerem em casa após o casamento e a vinda dos filhos, elas têm entrado no mercado de trabalho após o ingresso de seus filhos na escola.

${ }^{3}$ Para Jatobá (1989), mulheres com níveis mais elevados de instrução e conseqüentemente com melhores oportunidades no mercado de trabalho têm um custo de oportunidade de se inserir no mercado de trabalho alto em relação às tarefas domésticas. 
força de trabalho em relação às diversas fases do ciclo econômico. Nota-se, entretanto, que a participação das mulheres de renda mais baixa é menos vulnerável ao ciclo pela maior necessidade de complementar a renda familiar.

Reconhecemos a existência de diferenças estruturais entre famílias chefiadas por mulheres e aquelas chefiadas por homens e argumentamos que estas famílias diferem fundamentalmente no seu processo de alocação e/ou decisão interna. Concluímos, então, pela necessidade de uma análise que busque identificar os elementos básicos da contribuição da mulher ao processo de determinação da renda familiar, que deverá ter uma especificidade na dimensão de tipos de família. ${ }^{4}$

A importância relativa do subgrupo escolhido para análise pode ser comprovada na Täbela 1. Quando decompomos a população de mulheres entre 15 e 54 anos de idade de acordo com sua posição relativa no domicílio, observamos que $56,9 \%$ delas eram cônjuges em 1983, decrescendo para $55,6 \%$ em 1988. Conseqüentemente, de todas as mulheres com idade entre 15 e 54 anos, aproximadamente $55 \%$ se encontram na condição de cônjuges no período analisado.

Notamos também o crescimento de importância (relativa e absoluta) das famílias chefiadas por mulheres entre 1983 e 1988. A proporção de mulheres chefes de família, em termos relativos, cresceu de 7,7\% em 1983 para 9,2\% em 1988. Em termos absolutos, isto é, levando-se em conta o crescimento populacional, isto significa que, como um grupo, as mulheres chefes de família cresceram $6,7 \%$ ao ano neste período. Computando-se as mesmas estatísticas para as mulheres cônjuges encontramos um crescimento em termos absolutos de $2,6 \%$ ao ano e um decréscimo em termos relativos de $1,3 \%$. Note-se que a subpopulação de mulheres entre 15 e 54 anos cresceu $3,04 \%$ ao ano, segundo projeções com dados das PNADs. A evidência observada, que sugere um crescimento rápido das famílias chefiadas por mulheres, é um indicador importante de bem-estar da população, pois são exatamente essas famílias as que mais provavelmente podem ser associadas com os problemas clássicos de pobreza e deficiências estruturais no processo de geração de renda familiar [Barros e Mendonça (1990)].

\footnotetext{
${ }^{4}$ Quando analisamos especificamente a participação da mulher cônjuge no mercado de trabalho centramos nossa análise nas farrulias nucleares (aquelas constituídas pelo marido, a mulher e "potencialmente" pelos filhos).
} 
Tabela 1.

Distribuição das mulheres entre

15 e 54 anos de idade por condição no domicílio - Brasil 1983/1988

\begin{tabular}{lcccccc}
\hline & Chefe & Cônjuge & Filha & Parente & $\begin{array}{c}\text { Agreg. } \\
\text { Pens. }\end{array}$ & $\begin{array}{c}\text { Total } \\
(\mathrm{mil} .)\end{array}$ \\
\hline 1983 & 7.69 & 56.93 & 28.74 & 5.78 & 0.86 & 31623 \\
1984 & 7.92 & 56.71 & 28.95 & 5.62 & 0.80 & 32441 \\
1985 & 8.02 & 56.58 & 28.82 & 5.85 & 0.73 & 33945 \\
1986 & 8.30 & 56.47 & 28.52 & 5.88 & 0.83 & 34731 \\
1987 & 8.42 & 56.20 & 28.30 & 6.17 & 0.91 & 35723 \\
1988 & 9.16 & 55.61 & 28.20 & 6.11 & 0.92 & 36742 \\
Mudanca \% & & & & & & \\
$83-88$ & 38.40 & 13.50 & 14.01 & 22.82 & 24.30 & 16.19 \\
Taxa & 6.72 & 2.56 & 2.66 & 4.20 & 4.45 & 3.05 \\
\hline
\end{tabular}

FONTE: Tabulapōes dos autores utilizando-se amostragens feitas pelas PNADs

Decompondo-se o crescimento populacional segundo a condição no domicílio (ou seja, entre o grupo de mulheres chefes, cônjuges, filhas e outras) constatamos um crescimento tanto no grupo das mulheres cônjuges quanto das chefes. Em termos relativos esse crescimento só se verificou no último grupo, o que poderia sugerir uma mudança na estrutura domiciliar, no periodo de 1983/88, ocorrendo entre o grupo de mulheres cônjuges e o de mulheres chefes.

Se a Tabela 1 mostra que as mulheres cônjuges constituem a maioria das mulheres do grupo etário de interesse, as Tabelas 2 e 3 mostram que elas também são numérica e absolutamente importantes dentre o sub-grupo de mulheres que participam do mercado de trabalho brasileiro. A taxa de participação das mulheres cônjuges evolui de $34,5 \%$ para $39,7 \%$ em 1988 . O aumento na proporção de cônjuges trabalhando ou procurando trabalho no período (um crescimento de $5,3 \%$ ) representa uma das mais importantes mudanças estruturais observadas no mercado de trabalho no passado recente, significando uma entrada no mercado de trabalho de aproximadamente 1,9 milhão de trabalhadoras cônjuges (passando de 6 milhões em 1983 para 7,9 milhões em 1988). ${ }^{5}$

$\overline{5}$ Este crescimento significativo da PEA de mulheres cônjugss parece indicar 
Tabela 2.

Proporção das mulheres entre

15 e 54 anos de idade por condição de atividade - Brasil 1983/1988

\begin{tabular}{lcccccc}
\hline & \multicolumn{3}{c}{ Trabalho } & \multicolumn{3}{c}{ Procura Trabalho } \\
\cline { 2 - 7 } & Chefe & Cònjuge & Filha & Chefe & Cònjuge & Filha \\
\hline 1983 & 67.30 & 33.54 & 49.37 & 2.63 & 0.92 & 4.86 \\
1984 & 68.19 & 33.92 & 49.91 & 2.33 & 0.83 & 4.80 \\
1985 & 68.06 & 35.55 & 52.29 & 1.83 & 0.70 & 4.05 \\
1986 & 69.11 & 36.14 & 53.15 & 1.23 & 0.50 & 2.92 \\
1987 & 70.21 & 38.41 & 53.47 & 1.75 & 0.90 & 4.18 \\
1988 & 70.16 & 38.81 & 53.04 & 2.34 & 0.84 & 4.60 \\
Mudanca \% & & & & & & \\
$83-88$ & 2.86 & 5.27 & 3.67 & -0.29 & -0.08 & -0.26 \\
\hline
\end{tabular}

FONTE: Tabulapōes dos autores utilizando-se amostragens feitas pelas PNADs

Embora tenhamos observado aumentos expressivos na taxa de participação das esposas cônjuges no mercado de trabalho, mesmo quando comparados àqueles observados para o grupo de mulheres chefes de família, essas taxas ainda estão muito ábaixo daquelas observadas em países desenvolvidos, como também se verificou no Relatório Padrão (1989). Segundo esse, Relatório Padrão (1989) as taxas de participação femininas no mercado de trabalho brasileiro apresentam um padrão semelhante àquele verificado pelos países latino-americanos, caracterizando-se por apresentarem distribuições unimodais, assimétricas à direita, com pico da curva no grupo etário de 20-24 ou 25 -29 anos. Na verdade, o Relatório Padrão (1989) associa a existência de um padrão brasileiro ao latino-americano, como também constata que os niveis de participação feminina destes países, assim como o do Brasil, se situam bem abaixo daqueles verificados para países tipicamente desenvolvidos, em particular os Estados Unidos, Canadá, França, Inglaterra e Alemanha. ${ }^{6}$

uma mudança permanente e nāo transitória da participação das mulheres no mercado de trabalho brasileiro.

${ }^{6}$ No Relatório Padrão (1989) procura-se, dentre outras coisas, definir hipóteses sobre possíveis cenários de evolução das taxas de participação por idade e sexo, dos países latino-americanos e dos países mais desenvolvidos (Estados Unidos, Canadá, países da Europa Ocidental e Meridional, e do Leste 
Para o Brasil como um todo, a participação das mulheres chefes de família evoluiu de $70 \%$ em 1983 para $72,5 \%$ em 1988 , niveis que podem ser considerados baixos quando levamos em consideração a ausência de mecanismos de assistência social efetiva no Brasil.

Quando decompomos as mulheres que trabalhavam ou tinham trabalho por condição no domicílio (veja Tabela 3 ), verificamos que a estrutura do mercado de trabalho permaneceu relativamente estável neste periodo. A proporção de mulheres cônjuges cresceu de 46,1\% em 1983 para 46,7\% em 1988, enquanto que a proporção das mulheres chefes de família cresceu de $12,5 \%$ em 1983 para 13,9\% em 1988. Essas mudanças não são provavelmente significativas dadas as características das amostras utilizadas. ${ }^{7}$ A estabilidade observada na composição relativa da força de trabalho é uma característica interessante e que decorre da conjugação de efeitos distintos mas que, no cômputo geral, se compensam. Por um lado observamos um aumento relativo na importância das famílias chefiadas por mulheres; por outro lado, observamos também que a proporção das mulheres cônjuges que trabalham aumenta relativamente a todos os outros grupos. No agregado, a proporção das mulheres que trabalhavam ou tinham trabalho aumentou de 41,5\% em 1983 para 46,3\% em 1988, refletindo tanto o aumento de participação das mulheres cônjuges como o aumento de importância relativa das famílias chefiadas por mulheres, que cresceram tanto em termos absolutos quanto relativos.

Algumas características gerais das mulheres que participam no mercado de trabalho são apresentadas nas Tabelas 4 e 5 . Observa-se que, dentre as trabalhadoras, as mulheres cônjuges são relativamente mais jovens ( 35 anos de idade em média) do que as chefes de família ( 39 anos em média), e trabalham jornadas mais curtas ( 37 horas) do que as chefes de família (42 horas). Embora cônj uges assim como filhas apresentem, ao longo do período $1983-$ 88 , um ligeiro crescimento na idade, no caso das mulheres chefes isto se dá de forma inversa. Mais uma vez, isto é consistente com

Euro peu), através da construção de grupos de países mais homogêneos.

${ }^{7}$ Note- se que as estatísticas estimadas baseiam-se nas amostras estratificadas das PNADs, induzindo-se, consequentemente, a um erro de previsão superior ao computado, usando-se simplesmente os pesos supridos pelo IBGE como pond eradores. 
Tabela 3.

Distribuição das mulheres ocupadas entre

15 e 54 anos de idade Brasil - 1983/1988

\begin{tabular}{lcccccc}
\hline & Chefe & Cônjuge & Filha & Parente & $\begin{array}{c}\text { Agre. } \\
\text { Pens. }\end{array}$ & $\begin{array}{c}\text { Ocupadas } \\
\text { Total }(\bullet)\end{array}$ \\
\hline 1983 & 12.48 & 46.05 & 32.22 & 6.13 & 1.12 & 41.47 \\
1984 & 12.88 & 45.91 & 34.49 & 5.69 & 1.03 & 41.90 \\
1985 & 12.51 & 46.10 & 34.54 & 5.90 & 0.95 & 43.63 \\
1986 & 12.93 & 45.98 & 34.16 & 5.88 & 1.05 & 44.39 \\
1987 & 12.87 & 46.97 & 32.92 & 6.16 & 1.08 & 45.96 \\
1988 & 13.89 & 46.65 & 32.33 & 6.03 & 1.10 & 46.26 \\
$\begin{array}{l}\text { Mudanf \% } \\
\text { 83-88 }\end{array}$ & 1.41 & 0.60 & -1.89 & -0.10 & -0.02 & 4.79 \\
\hline
\end{tabular}

FONTE: Tabulapōes dos autores utilizando-se amostragens feitas pelas PNADs (*) Relacão entre o total de mulheres ocupadas entre 15 e 54 anos e o total da populaạa feminina situada neste grupo etário.

a hipótese de que poderia estar ocorrendo uma transferência de cônjuges (e também de filhas) para o grupo de chẹfes.

Quando comparamos a renda do trabalho entre os dois grupos, observamos que a diferença de renda tem favorecido as chefes durante todo o período de análise, apresentando alguma evidência

Tabela 4.

Idade das mulheres ocupadas entre

15 e 54 anos de idade Brasil - 1983/1988

\begin{tabular}{lccc}
\hline & \multicolumn{3}{c}{ Idade } \\
\cline { 2 - 4 } & Chefe & Cônjuge & Filha \\
\hline 1983 & 39.45 & 35.18 & 22.70 \\
1984 & 38.97 & 35.25 & 22.82 \\
1985 & 39.05 & 35.21 & 22.84 \\
1986 & 39.10 & 35.44 & 22.99 \\
1987 & 39.29 & 35.31 & 23.20 \\
1988 & 39.25 & 35.69 & 23.28 \\
Mudanfa \% & & & \\
$83-88$ & -0.20 & 0.51 & 0.58 \\
\hline
\end{tabular}

FONTE: Tabulapōes dos autores utilizando-se amostragens feitas pelas PNADs. 


\section{Tabela 5.}

Salários e horas trabalhadas das mulheres

ocupadas entre 15 e 54 anos de

idade - Brasil 1983/1988

\begin{tabular}{lcccccc}
\hline & \multicolumn{3}{c}{ Salário } & \multicolumn{3}{c}{ Horas Trabalhadas } \\
\cline { 2 - 7 } & Chefe & Cônjuge & Filha & Chefe & Cônjuge & Filha \\
\hline 1983 & 2.34 & 2.09 & 1.54 & 42.19 & 36.97 & 42.30 \\
1984 & 2.39 & 2.21 & 1.50 & 42.62 & 37.19 & 42.05 \\
1985 & 2.86 & 2.56 & 1.68 & 42.64 & 37.45 & 42.21 \\
1986 & 3.93 & 3.59 & 2.40 & 42.15 & 37.30 & 42.06 \\
1987 & 3.23 & 2.80 & 1.87 & 41.80 & 37.14 & 41.86 \\
1988 & 3.25 & 2.77 & 1.88 & 41.46 & 36.83 & 41.54 \\
Mudanca \% & & & & & & \\
83-88 & 0.91 & 0.68 & 0.34 & & & \\
\hline
\end{tabular}

FONTE: Tabulapōes dos autores utilizando-se amostragens feitas pelas PNADs

de crescimento. Portanto, quando levamos em consideração a diferença de jornadas de trabalho computando a renda do trabalho associada a uma jornada típica de 40 horas (denotado salário normalizado para 40 horas) estes diferenciais de salários quase que totalmente desaparecem, e concluímos pela inexistência desses diferenciais. ${ }^{8}$ A título de ilustração, podemos notar que, para o ano de 1984, o salário normalizado tanto para chefes quanto para cônjuges é de 0,06 .

\section{Uma análise da representatividade das áreas metropo- litanas.}

$\mathrm{Na}$ seção anterior procuramos estabelecer algumas das principais regularidades associadas à participação feminina no mercado de trabalho brasileiro e à sua evolução no período 198388. Nessa seção buscamos avaliar a representatividade, para esse mesmo mercado, de inferências e observações baseadas em dados coletados para as principais áreas metropolitanas. Pela maior disponibilidade de informações que dizem respeito à fecundidade da mulher, baseamos esta análise somente em informações derivadas da PNAD de 1984.

\footnotetext{
${ }^{8}$ Entendese por salário normalizado para 40 horess a razāo entre o salário auferido e o número de horas trabaihadas, na semana de referência.
} 
Tabela 6.

Distribuição das mulheres entre

15 e 54 anos de idade por áreas metropolitanas de residência em 1984

\begin{tabular}{lcccccc}
\hline & Chefe & Cônjuge & Filha & Parente & $\begin{array}{c}\text { Agreg. } \\
\text { Pens. }\end{array}$ & $\begin{array}{c}\text { Total } \\
\text { (mil.) }\end{array}$ \\
\hline Rio de Janeiro & 10.26 & 53.29 & 29.28 & 6.36 & 0.81 & 2978 \\
São Paulo & 9.19 & 57.61 & 26.23 & 6.10 & 0.87 & 4291 \\
Recife & 10.03 & 48.76 & 32.82 & 7.71 & 0.68 & 737 \\
Fortaleza & 8.46 & 49.34 & 32.98 & 7.86 & 1.36 & 515 \\
Salvador & 11.42 & 50.13 & 29.29 & 8.26 & 0.90 & 556 \\
Belo Horizonte & 9.52 & 52.38 & 32.33 & 5.11 & 0.66 & 848 \\
Curitiba & 9.62 & 59.59 & 24.91 & 4.69 & 1.19 & 501 \\
Porto Alegre & 10.46 & 61.07 & 21.89 & 5.26 & 1.32 & 774 \\
Reg. Urbana & 9.11 & 55.27 & 28.63 & 6.03 & 0.96 & 24684 \\
Brasil & 7.92 & 56.71 & 28.95 & 5.62 & 0.80 & 32441 \\
\hline
\end{tabular}

FONTE: Tabulacōes dos autores utilizando-se amostragens feitas pelas PNADs.

Gostariamos de analisar o mercado de trabalho metropolitano, primeiro, por se constituir num segmento importante do mercado de trabalho feminino brasileiro (um terço da população em análise reside nas áreas metropolitanas); e, segundo, pela capacidade de prover indicadores do comportamento do mercado de trabalho urbano e nacional num ambiente mais controlado. Com relação zo ultimo ponto, embora os residentes nas áreas metropolitanas se diferenciem em caracteristicas importantes da população nacional, em geral os diferentes indicadores têm apresentado magnitudes semelhantes.

Em 1984, segundo dados da PNAD, a população de mulheres entre 15 e 54 anos de idade foi estimada em 32,4 milhões (veja Tabela 6). Dentre essas, 11,2 milhões moravam nas áreas metropolitanas do Rio de Janeiro, São Paulo, Recife, Fortaleza, Salvador, Belo Horizonte, Curitiba e Porto Alegre (Belém e Brasilia foram excluídas da. nossa análise). Desta forma, tem-se que aproximadamente um terço da população objeto deste estudo residia em áreas metropolitanas.

Quando classificamos as mulheres por condição no domicílio e por área metropolitana de residência, observamos: (a) por um lado, a proporção de mulheres chefes de familia variando de um 
mínimo de 8,5\% em Fortaleza a um máximo de 11,4\% em Salvador; e (b) por outro lado, a proporção de cônjuges variando entre $48,8 \%$ em Recife e $61,1 \%$ em Porto Alegre.

Observando-se que, para a região urbana a proporção de mulheres chefes de família é de $9,1 \%$, a de cônjuges $55,3 \%$, enquanto que, para o Brasil como um todo, esta proporção é de $7,9 \%$ e $56,7 \%$, respectivamente, concluímos: primeiramente, que a ocorrência de domicilios com mulheres chefes é um fenômeno relativamente mais importante nas regiões urbanas e que assume importância ainda maior nas áreas metropolitanas; segundo, que as variações das proporções de cônjuges entre as regiōes metropolitanas são fortemente associadas ao nivel de desenvolvimento econômico específico da região em análise. Por um lado, nas regiões mais pobres (como Recife, Salvador e Fortaleza) observamos baixas proporções de cônjuges e altas proporções de filhas na população e, por outro lado, nas regiões mais ricas (São Paulo, Curitiba e Porto Alegre) observamos maiores proporções de cônjuges e menores proporções de filhas.

Essa análise sugere que diferenças relativas no tamanho das famílias, na distribuição etấria:de seus memhros, e no processo de constituição de novas famílias combinam-se para gerar uma estrutura domiciliar feminina diferenciada entre as áreas metropolitanas, além de distinta da observada para o Brasil cumo um todo.

Buscando caracterizar melhor as diferenças entre as áreas metropolitanas acima destacadas, computamos a proporção dos diferentes grupos classificados por condição no domicílio, região de residência e posição na PEA. Os resultados estão apresentados na Tabela 7. A proporção de mulheres chefes fora da PEA varia de um mínimo de $23 \%$ em São Paulo e um máximo de $37 \%$ em Recife. A proporção de cônjuges fora da PEA varia de um mínimo de $57 \%$ em Porto Alegre a um máximo de $67 \%$ em Recife. Para o Brasil, $29 \%$ das mulheres chefes e $65 \%$ das mulheres cônjuges estão fora da PEA. Dessas proporções pode-se concluir que: primeiro, as taxas de participação são relativamente mais altas nas áreas metropolitanas do que em outras regiōes do Brasil (Recife é uma clara exceção) ${ }^{9}$ segundo, que variações entre áreas

\footnotetext{
${ }^{9}$ Note-se que, nesta parte da análise, excluiu-se o grupo de mulheres constituido pelas filhas.
} 
Tabela 7.

Proporção das mulheres entre 15 e 54 anos de idade por condição de atividade segundo áreas metropolitanas de residência em 1984

\begin{tabular}{lcccccc}
\hline & \multicolumn{2}{c}{ Trabalha } & \multicolumn{2}{c}{ Procura Trabalho } & \multicolumn{2}{c}{ Fora da PEA } \\
\cline { 2 - 7 } & Chefe & Cônjuge & Chefe & Cônjuge & Chefe & Cônjuge \\
\hline Rio de Janeiro & 69.96 & 37.29 & 3.29 & 1.41 & 26.75 & 61.30 \\
São Paulo & 73.02 & 34.60 & 4.23 & 1.66 & 22.75 & 63.79 \\
Recife & 59.38 & 31.23 & 3.26 & 1.34 & 37.36 & 67.43 \\
Fortaleza & 71.58 & 40.52 & 2.45 & 0.88 & 25.97 & 58.60 \\
Salvador & 77.32 & 39.20 & 1.89 & 1.25 & 20.79 & 59.55 \\
Belo Horizonte & 67.15 & 33.34 & 2.77 & 0.91 & 30.08 & 65.75 \\
Curitiba & 69.06 & 33.76 & 1.85 & 0.93 & 29.09 & 65.31 \\
Porto Alegre & 73.29 & 41.64 & 2.32 & 1.54 & 24.39 & 56.82 \\
Reg. Urbana & 68.39 & 33.88 & 2.57 & 1.08 & 29.04 & 65.04 \\
Brasil & 68.19 & 33.92 & 2.33 & 0.83 & 29.48 & 65.25 \\
\hline
\end{tabular}

FONTE: Tabulapōes dos autores utilizando-se amostragens feitas pelas PNADs.

metropolitanas não estão necessariamente associadas ao nivel de desenvolvimento da região. Notamos, por exemplo, que se por um lado, em São Paulo, Curitiba e Belo Horizonte $34 \%$ das mulheres cônjuges trabalhavam, por outro lado, em Fortaleza, Salvador e Porto Alegre essa proporção aumenta para $40 \%$.

Tomando-se como ótica a participação na força de trabalho feminina local decompomos a sub-população das trabalhadoras segundo a condição no domicilio para diferentes regiões de residência (Tabela 8). Nessa Tabela observamos que, entre as trabalhadoras, a proporção de cônjuges varia de $40 \%$ em Belo Horizonte a $53 \%$ em Porto Alegre. Para as outras regiões metropolitanas essa proporção situa-se entre $43 \%$ e $46 \%$, enquanto que para o Brasil este número é $46 \%$.

As mulheres cônjuges encontrar-se, conseqüentemente, relativamente pouco representadas no universo das mulheres ocupadas das áreas metropolitanas quando esta participação é comparada com sua participação na PEA feminina do Brasil como um todo. Porém, se excluímos da análise Porto Alegre, concluímos que existe uma relativa estabilidade das taxas de participação de cônjuges nas regiões.

Comparando-se a idade média dos diversos sub-grupos da 
Tabela 8.

Distribuição das mulheres entre

15 e 54 anos de idade por áreas metropolitanas

de residência em 1984

\begin{tabular}{lcccccc}
\hline & Chefe & Cônjuge & Filha & Parente & $\begin{array}{c}\text { Agreg. } \\
\text { Pens. }\end{array}$ & Total \\
\hline Rio de Janeiro & 16.38 & 45.33 & 30.76 & 6.31 & 1.22 & 43.84 \\
São Paulo & 14.51 & 43.09 & 33.70 & 7.27 & 1.43 & 46.26 \\
Recife & 16.83 & 43.03 & 33.12 & 6.41 & 0.61 & 35.39 \\
Fortaleza & 14.14 & 46.65 & 31.17 & 6.83 & 1.21 & 42.85 \\
Salvador & 20.65 & 45.99 & 24.05 & 8.31 & 1.00 & 42.74 \\
Belo Horizonte & 14.66 & 40.03 & 37.85 & 6.27 & 1.19 & 43.62 \\
Curitiba & 15.31 & 46.36 & 31.57 & 5.02 & 1.74 & 43.38 \\
Porto Alegre & 16.07 & 53.29 & 23.18 & 5.56 & 1.90 & 47.72 \\
Reg. Urbana & 14.74 & 44.28 & 33.57 & 6.15 & 1.26 & 42.30 \\
Brasil & 12.88 & 45.91 & 34.49 & 5.69 & 1.03 & 41.90 \\
\hline
\end{tabular}

FONTE: Tabulaçes dos autores utilizando-se amostragens feitas pelas PNADs.

força de trabalho localizados em áreas metropolitanas (Tabela 9) notamos: (a) uma relativa uniformidade entre as idades médias das mulheres chefes bem como entre cônjuges, não se podendo concluir o mesmo para as filhas; e, (b) alguma evidência tanto de que mulheres chefes residentes nas áreas metropolitanas são relativamente mais velhas, bem como de que cônjuges que residem nas áreas metropolitanas são relativamente mais jovens do que as respectivas populações de trabalhadoras definidas para o Brasil como um todo, não se podendo, novamente, extrair nenhum resultado mais claro para o sub-grupo das filhas.

Ademais, notamos uma relativa variabilidade nas condições de trabalho feminino entre as áreas metropolitanas (veja Tabela 10). Observamos que, tanto para mulheres chefes como para cônjuges nas áreas metropolitanas de Recife, Fortaleza, São Paulo, Curitiba e Porto Alegre, a jornada de trabalho tende a ficar acima d.a média nacional. Enquanto isso, nas áreas metropolitanas do Rio de Janeiro, Salvadọ e Belo Horizonte a jornada média de trabalho situa-se abaixo da média nacional. No que diz respeito ao salário, as mulheres chefes recebem, em média, salários superiores ao percebido pelas mulheres cônjuges, além de trabalharem um número de horas, em média, também superior ao das mulhe- 
Tabela 9.

Idade, das mulheres ocupadas entre 15 e 54 anos de idade por áreas metropolitanas - 1984

\begin{tabular}{lccc}
\hline & \multicolumn{3}{c}{ Idade } \\
\cline { 2 - 4 } & Chefe & Cônjuge & Filha \\
\hline Rio de Janeiro & 40.49 & 35.71 & 24.79 \\
São Paulo & 37.84 & 34.41 & 23.42 \\
Recife & 39.36 & 35.17 & 24.88 \\
Fortaleza & 38.42 & 35.97 & 25.40 \\
Salvador & 39.53 & 34.27 & 21.29 \\
Belo Horizonte & 40.24 & 34.55 & 21.79 \\
Curitiba & 39.97 & 33.95 & 21.16 \\
Porto Alegre & 39.75 & 34.68 & 21.70 \\
Reg. Urbana & 38.62 & 35.14 & 23.44 \\
Brasil & 38.97 & 35.25 & 22.82 \\
\hline
\end{tabular}

FONTE: Tabulaçōes dos autores utilizando-se amostragens feitas pelas PNADs.

Tabela 10.

Salário e horas trabalhadas das mulheres ocupadas entre 15 e 54 anos de idade por áreas metropolitanas - 1984

\begin{tabular}{lcccccc}
\hline & \multicolumn{3}{c}{ Salário } & \multicolumn{3}{c}{ Horas Trabalhadas } \\
\cline { 2 - 7 } & Chefe & Cônjuge & Filha & Chefe & Cônjuge & Filha \\
\hline Rio de Janeiro & 2.90 & 2.60 & 1.88 & 41.10 & 36.53 & 41.28 \\
São Paulo & 3.44 & 3.00 & 2.46 & 44.78 & 38.97 & 42.82 \\
Recife & 1.87 & 2.26 & 1.61 & 43.91 & 39.35 & 44.39 \\
Fortaleza & 2.16 & 2.23 & 1.48 & 43.02 & 36.90 & 40.17 \\
Salvador & 3.09 & 3.16 & 2.00 & 41.56 & 36.69 & 39.31 \\
Belo Horizonte & 2.55 & 2.69 & 1.59 & 41.29 & 34.64 & 42.35 \\
Curitiba & 3.27 & 2.65 & 1.83 & 43.02 & $38 / 97$ & 44.04 \\
Porto Alegre & 3.67 & 2.96 & 2.12 & 42.23 & 39.42 & 42.49 \\
Reg. Urbana & 2.59 & 2.49 & 1.65 & 42.85 & 37.48 & 42.88 \\
Brasil & 2.39 & 2.21 & 1.50 & 42.62 & 37.19 & 42.05 \\
\hline
\end{tabular}

FONTE: Tabulapōes dos autores utilizando-se amostragens feitas pelas PNADs. 
res cônjuges. No final tem-se que, o salário normalizado tanto para chefes quanto para cônjuges não se diferencia, como no caso anterior.

\section{Conclusōes.}

O presente trabalho investigou primeiramente as características gerais da participação feminina no mercado de trabalho. Mostramos que as mulheres cônjuges como um grupo representam uma proporção importante das trabalhadoras no mercado de trabalho brasileiro.

Em linhas gerais, os dados analisados para o período de 1983 a 1988 denotaram questões que merecem destaque.

Primeiro, que as mulheres cônjuges representam parcela bem significante do mercado de trabalho brasileiro, tendo crescido, ao longo do período $83 / 88,2,6 \%$ em termos absolutos, embora, em termos relativos tenha ocorrido um decréscimo de 1,3\%. Atrelado a este crescimento verificamos, para o mesmo período, um crescimento tanto em termos absolutos quanto relativos das mulheres chefes de família. Este é um importante indicador de deficiências estruturais no processo de geração de renda familiar e associado a problemas clássicos de pobreza.

Segundo, que em relação a algumas características gerais (no que diz respeito ao mercado de trabalho e a características individuais) podemos destacar três (3) pontos, a constar que (i) as mulheres cônjuges (assim como as filhas) são relativamente mais jovens que as mulheres chefes, enquanto que ao longo do período $83 / 88$ a idade média das primeiras tem apresentado ligeiro decréscimo, ocorrendo o contrário para as chefes; (ii) as jornadas de trabalho das chefes são mais longas que das demais; e, (iii) os salários auferidos por elas (mulheres chefes) são também superiores àqueles percebidos para cônjuges e filhas.

Argumentamos, adicionalmente, que embora tenhamos identificado diferenças de comportamento (com relação a participação no mercado de trabalho) associadas a residência em áreas metropolitanas distintas, essas diferenças não são grañdes o suficiente para invalidar inferências para o comportamento agregado baseado em indicadores construídos restritamente para as áreas metropolitanas. O que cabe aqui ressaltar é a existência de um diferencial de taxas de participação entre as regiões metropolitan as e a região urbana favorável à primeira (a única exceção é 
a região metropolitana de Recife). Esse mesmo comportamento é observado para o caso das taxas de participação das mulheres chefes de domicílios, embora não tenhamos observado um padrão claro para as mulineres cônjuges.

\section{Referências}

Barros, R. P. de e Mendonça, P. S. R. de. Família e Distribuição de Renda: o Impacto da Participação das Esposas no Mercado de Trabalho. PPE, no prele, 1990.

Bilac, D. E. Fúmilias de Trabalhadores: Estratégias de Sobrevivência; Organização Familiar em uma Cidade Paulista. Símbolo, (Coleção Ensaio e Memória, 9), São Paulo, 1978.

Costa, L. Avanço da participação feminina: uma tentativa de explicação. In VII Encontro Nacional de Estudos : nais. Caxambu, out/1990.

Durand, J. D. The Labor Force in Economic Development: a Companison of International Census Data, 1946-66. Princenton University Press, Princenton,, 1975.

Jatobá, J. Participação na Força de Trabalho e. Ciclo Econômico: Brasil, 197€-86. Rio de Janeiro, ( $\Lambda$ spectos Teóricos e Metodológicos). IPEA / INPES, Texto para Discussão, 1989.

Kreps, J. Sex in the Market Place: American Women at Work. Baltimore, the Johns Hopkins University Press, 1971.

Kreps, J. \& Clark, R. Sex, Age and Work: the Changing Composition of the Labor Force. Baltinore, the Johns Hopkins University Press, 1975.

Miaddala, G. S. Introduction to econometrics. New York, Macmillan Publishing Company, 472, 1988.

Medice, A. IBGE. Perfil Estatístico de Cricinças e Mães no Brasil: Características Sócio-Demográficas, 1970-1977. Rio de Janeiro, 1982.

Oliveira, A. M. M. e Santos, E. C. A participação das mulheres no mercado de trabalho: uma análise das taxas de atividade femininas - Brasil 1984/1987. In VII Encontro Nacional de Estudos Populacionois. Caxambu, out/1990.

Padrão demográfico brasileiro e a previdência social MPAS: Brasília CEDEPLAR: Belo Horizonte, SEADE: São Paulo 1989. (Relatório Final). 
Pastore, J. e Zylberstajn, H. e Pagotto, C. S. Mudança, Social e Pobreza no Brasil: 1970-1980. (o que ocorreu com a família brasileira) São Paulo, Pioneira, 1983.

Paiva, P. T. A. A mulher no mercado de trabalho urbano. Em: anais do segundo encontro nacional de estudos populacionais, São Paulo, 2:842-895, 1980.

Schultz, T. P. Testing the neoclassical model of family labor supply and fertility. Yale University. (Mimeo), 1990.

Silva, R. M. R. da. Famílias. em: IBGE. Perfil estatístico de crianças e mães no Brasil: características sóciodemográficas, 1970-77, 71-118, 1982, Rio de Janeiro.

Zylberstajn, H.; Pagotto, C. S.; e Pastore, J. A mulher e o Menor na Força de Trabalho. São Paulo, Nobel; Brasilia, Ministério do Trabalho, 1985. 
